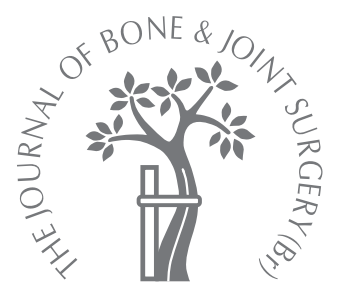
D. Pitts,
D. I. Rowley,
J. L. Sher

From TORT Centre, Ninewells Hospital and Medical School and Wansbeck General Hospital, Northumberland, England

\footnotetext{
D. Pitts, BSc, MCIPD, Surgical Education Development Advisor D. I. Rowley, BMed Biol, MD, FRCS

University Department of Orthopaedics \& Trauma Surgery

TORT Centre, Ninewells Hospital and Medical School, Dundee DD1 9SY, UK.

J. L. Sher, BSc, FRCS Wansbeck General Hospital, Woodhorn Lane, Ashington, Northumberland NE63 9JJ, UK.

Correspondence should be sent to Professor D. I.

Rowley; e-mail:

d.i.rowley@dundee.ac.uk

(C)2005 British Editorial Society of Bone and Joint Surgery doi:10.1302/0301-620X.87B9. $16434 \$ 2.00$

$J$ Bone Joint Surg [Br]

2005;87-B:1187-91.
}

\title{
Assessment of performance in orthopaedic training
}

The reliable measurement of performance is a problem faced by training authorities worldwide. At a recent international orthopaedic conference, none of a group of experienced orthopaedic educators could report significant progress on this issue.

The current Record of In Training Assessment (RITA) process which relies on simple assessment forms filled in by trainers and trainees is regarded widely as inadequate and lacking in objectivity. More robust evidence is needed.

The Orthopaedic Competence Assessment Project (OCAP), a combined initiative of the Education Committee of the British Orthopaedic Association and the Specialist Advisory Committee (SAC) in Trauma \& Orthopaedics was given the remit to improve training through a competency-based portfolio of coaching and assessment tools. These instruments had to be easily understood by a range of trainers and trainees, not time-consuming and simple to apply.

OCAP recognises the need for a battery of tools to address the different aspects of performance. These have been described by Miller ${ }^{1}$ who refers to different levels of assessment which are best tested in different ways (Fig. 1). In Miller's pyramid, 'knowing' and 'knowing

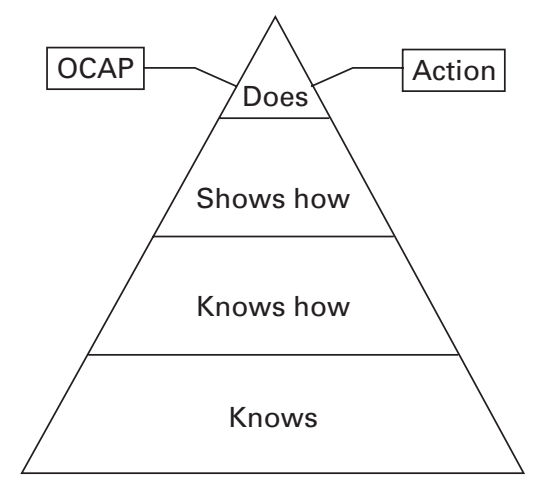

Fig. 1

how' are reliably tested in well-defined examination formats and set-piece assessments, such as clinical examinations and orals can monitor 'shows how'. However, 'does' requires realtime assessment and it is to this need that OCAP has responded.

Any assessment needs to be valid and reliable. Validity is well served by real clinical situations. Reliability, which is equally important, requires a tool which is practical, consistent and easy to repeat.

The instruments described below follow the principles of Miller ${ }^{1}$ and Norman. ${ }^{2}$ In this arti-

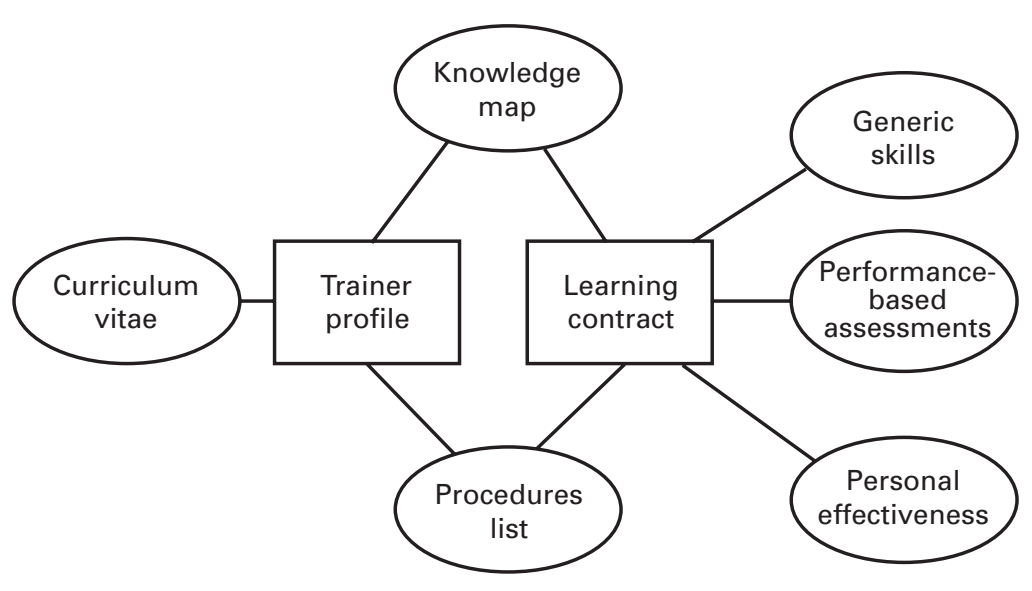

Fig. 2 
PROCEDURES PROFILE

\begin{tabular}{|c|c|c|c|c|c|}
\hline \multirow[t]{2}{*}{ Procedure } & \multicolumn{5}{|c|}{ Assessment } \\
\hline & 1 & 2 & 3 & 4 & 5 \\
\hline \multicolumn{6}{|l|}{ Hip } \\
\hline \multicolumn{6}{|l|}{ Slipped upper femoral epiphysis } \\
\hline Slipped upper femoral epiphysis open reduction & & A & & & G \\
\hline Slipped upper femoral epiphysis pinning & & A & & & G \\
\hline \multicolumn{6}{|l|}{ THR } \\
\hline THR cemented & & A & & & G \\
\hline THR hybrid & A & & & G & \\
\hline THR surface replacement & A & & & G & \\
\hline THR uncemented & & A & & & G \\
\hline
\end{tabular}

Fig. 3

An extract from Procedures Profile showing trainee's estimate of their position at start (A) and goal (G) for end of attachment (1, know about; 2, seen; 3, managed with help; 4, managed; 5, confident to manage).

\section{KNOWLEDGE PROFILE}

\begin{tabular}{|c|c|c|c|c|}
\hline \multirow[t]{2}{*}{ Topic } & \multicolumn{4}{|c|}{ Progress plan } \\
\hline & 1 & 2 & 3 & 4 \\
\hline \multicolumn{5}{|l|}{ Hip } \\
\hline \multicolumn{5}{|l|}{ Clinical assessment } \\
\hline $\begin{array}{l}\text { A sound knowledge of clinical assessment of the hip, } \\
\text { lumbosacral spine and knee. Particular reference } \\
\text { should be paid to the gait, the Trendelenburg sign, } \\
\text { limb length, loss of movement and deformity at the } \\
\text { joint }\end{array}$ & & & A & G \\
\hline $\begin{array}{l}\text { - The trainee needs to be well informed of current } \\
\text { opinion regarding aetiopathogenesis, clinical } \\
\text { presentation and appropriate investigation of: }\end{array}$ & & A & & G \\
\hline $\begin{array}{l}\text { Proximal femoral fractures (intracapsular, } \\
\text { extracapsular) and simple fracture dislocations of } \\
\text { the hip }\end{array}$ & & & A & G \\
\hline o Osteoarthritis and the inflammatory arthropathies & & $A$ & G & \\
\hline o Perthes' disease & & A & G & \\
\hline O Slipped upper femoral epiphysis & & A & G & \\
\hline O Septic arthritis & & A & G & \\
\hline o Osteonecrosis & & A & G & \\
\hline $\begin{array}{l}\text { O Soft-tissue conditions around the hip (snapping } \\
\text { hip, gluteus medius tendonitis, etc) }\end{array}$ & & A & G & \\
\hline
\end{tabular}

Fig. 4

An extract from Knowledge Map showing trainee's estimate (A) of their position at start and agreed goal (G) for end of attachment (1, knows of; 2, knows basic concepts; 3, knows generally; 4, knows specifically and broadly).

cle, we describe the instruments, their validation and how reliability might be ensured.

\section{OCAP instruments (Fig. 2)}

The package consists of two types of instrument: agenda setting/coaching, and assessment.

The agenda-setting instruments of the trainer profile have been piloted and found to be acceptable in two large training programmes in the United Kingdom. The assess- ment instruments are also complete in terms of validity, but reliability studies are ongoing. The personal effectiveness instruments which coach and test generic skills are at an early stage of development.

How OCAP works. In advance of an attachment, trainers and trainees exchange information about themselves. A trainee's portfolio is shared with the trainer who provides a personal profile for the trainee. This profile is easily formatted from a database of 'knowledge' and 'procedures' and 
Table I. List of performance-based assessments

\begin{tabular}{ll}
1 & Clinic activity in trauma and orthopaedics \\
2 & Debridement of a wound \\
3 & Carpal tunnel decompression \\
4 & Digital and palmar fasciectomy \\
5 & Diagnostic arthroscopy and simple arthroscopic procedures \\
6 & Total knee replacement \\
7 & First ray surgery to the foot \\
8 & Total hip replacement \\
9 & Lumbar discectomy \\
0 & Compression hip screw for intertrochanteric fracture neck of femur \\
1 & Hemiarthroplasty intracapsular fracture neck of femur \\
2 & Application of limb external fixator \\
3 & Operative fixation of Weber B fracture of ankle \\
4 & Fixation of patella fractures by tension band wiring \\
5 & Fixation olecranon fractures by tension band wiring \\
6 & Intramedullary nailing for femoral or tibial shaft fractures \\
7 & Tendon repair \\
8 & Closed management of fractures \\
\hline
\end{tabular}

outlines the surgical training available in an attachment. The profile describes the procedures the trainer performs regularly and the knowledge base to underpin this activity. Both parties then meet at the start of the attachment and draw up a learning agreement of which the key objectives are: to identify the trainee's level of knowledge and experience; to set realistic goals and expectations for the attachment; to agree the knowledge which should be acquired during the attachment and to define those aspects of the trainee's performance to be assessed at the end of the attachment.

The agreement needs regular review by both parties, including a formal review at mid-attachment. However, plans may have to change according to circumstances. For example, a target may become unrealistic due to unforeseen circumstances such as ill health or prove to be overly optimistic. At the end of the attachment, the goals need to be compared with achievement. This comparison provides evidence for the summative RITA.

Figure 3 is an extract from a Procedures Profile showing a trainee's estimate $(\mathrm{A})$ of their position at start of attachment and the goal for the end of the job (G).

Figure 4 is an extract from a Knowledge Map which similarly compares a trainee's estimate of their position at the start and finish of an attachment.

\section{Performance-based assessments}

A cornerstone of OCAP is the collection of performancebased assessments. These are formal, structured assessments of clinical activity (including surgical performance). They take a holistic approach, including understanding a problem, communicating, planning, operating and ensuring clear post-operative instructions.

Performance-based assessments identify and capture relevant activity, which is performed in sufficient numbers

Table II. The core content of performance-based assessments

\begin{tabular}{lll}
\hline I & Consent \\
C2 & Demonstrates sound knowledge of (contra) indications \\
C3 & Demonstrates sound knowledge of complications of surgery \\
C4 & Eemonstrates awareness of specific problems at surgery generated by the disease being treated \\
C5 & Explains likely outcome and time to recovery and checks understanding \\
II & Pre-operative planning \\
PL1 & Demonstrates recognition of anatomical and pathological abnormalities and operative strategy to deal with these \\
PL2 & Ability to make reasoned choice of appropriate device (if any) using appropriate investigations e.g. x-rays \\
PL3 & Checks equipment and device requirements with operating room staff \\
PL4 & Where applicable ensures the limb is marked \\
III & Pre-operative preparation \\
PR1 & Ensures proper and safe positioning of the patient on the operating table \\
PR2 & Ensures devices e.g. diathermy and tourniquet are deployed safely \\
PR3 & Arranges for and deploys supporting equipment e.g. imaging intensifiers effectively \\
PR4 & Adequately prepares a sterile operating field \\
IV & Exposure and closure \\
E1 & Demonstrates knowledge of optimum skin incision \\
E2 & Demonstrates respect for soft tissues including skin \\
E3 & Achieves an adequate exposure and identifies all structures correctly \\
E4 & Completes a sound reconstruction \\
E5 & Protects the wound properly with dressings and splints \\
V Intra-operative technique \\
IT1 & Follows a logical sequence or protocol for the procedure \\
IT2 & Adheres to hospital protocols and policies \\
IT3 & Anticipates and responds appropriately to variation \\
IT4+ & See individual performance-based assessments for detail \\
VI & Closing the loop \\
CL1 & Ensures the patient is transferred from operating table to bed \\
CL2 & Construct a clear operation note, retaining the equipment documentation and checking x-rays where appropriate \\
CL3 & Gives documented and sensible post-operative instructions \\
CL4+ & See individual performance-based assessments for detail \\
\hline
\end{tabular}


Table III. An example of a logbook correlation

\begin{tabular}{|c|c|c|c|c|c|c|c|c|}
\hline & & A & STS & STU & $\mathbf{P}$ & $\mathbf{T}$ & $\begin{array}{l}\text { Total exposure } \\
\text { in years } 1 \text { to } 6\end{array}$ & $\begin{array}{l}\text { Total actually performed } \\
\text { in years } 1 \text { to } 6\end{array}$ \\
\hline & All elective in Deanery $X$ & 353 & 314 & 137 & 190 & 7 & 1001 & 641 \\
\hline & All elective in Deanery $X$ & 391 & 223 & 84 & 247 & 20 & 965 & 554 \\
\hline 1 & Clinic activity in trauma and orthopaedics & & & & & & & \\
\hline 2 & Debridement of a wound & & & & & & & \\
\hline 3 & Hand - carpal tunnel decompression & 4 & 6 & 4 & 40 & 6 & 60 & 50 \\
\hline 4 & Hand Dupuytren surgery & 9 & 7 & 1 & 4 & 0 & 21 & 12 \\
\hline 5 & Knee arthroscopy with procedure & 24 & 21 & 23 & 38 & 1 & 107 & 82 \\
\hline 5 & Knee arthroscopy & 9 & 10 & 11 & 17 & 1 & 48 & 38 \\
\hline 5 & $\begin{array}{l}\text { Shoulder and elbow - shoulder arthroscopy } \\
\text { with procedure }\end{array}$ & 10 & 7 & 1 & 1 & 0 & 19 & 9 \\
\hline 5 & Shoulder and elbow - shoulder arthroscopy & 2 & 2 & 1 & 1 & 0 & 6 & 4 \\
\hline 6 & Joint replacement knee & 51 & 39 & 5 & 12 & 1 & 108 & 56 \\
\hline 7 & Foot and ankle - hallux valgus surgery & 13 & 10 & 1 & 7 & 1 & 32 & 18 \\
\hline 7 & Foot and ankle - lesser toe surgery & 5 & 6 & 2 & 6 & 0 & 19 & 14 \\
\hline 7 & Foot and ankle - midfoot and hindfoot surgery & 13 & 5 & 1 & 3 & 0 & 22 & 9 \\
\hline 8 & Joint replacement hip & 62 & 38 & 4 & 12 & 1 & 117 & 54 \\
\hline 9 & Spine - discectomy & 7 & 2 & 0 & 0 & 0 & 9 & 2 \\
\hline 9 & Spine - decompression & 6 & 2 & 0 & 0 & 0 & 8 & 2 \\
\hline 10 & Trauma - hip fractures (intracapsular) & 8 & 13 & 7 & 59 & 8 & 95 & 79 \\
\hline 11 & Trauma - hip fractures (extracapsular) & 3 & 6 & 7 & 47 & 10 & 73 & 60 \\
\hline 12 & Trauma - application of external fixator & 5 & 5 & 1 & 5 & 1 & 17 & 11 \\
\hline 13 & Trauma - ORIF* ankle & 5 & 10 & 4 & 33 & 4 & 56 & 47 \\
\hline 14 & Trauma - ORIF patella & 1 & 1 & 0 & 2 & 0 & 4 & 3 \\
\hline 15 & Trauma - ORIF olecranon & 1 & 2 & 1 & 5 & 1 & 10 & 8 \\
\hline 16 & Trauma - femoral nails & 6 & 9 & 3 & 8 & 1 & 27 & 20 \\
\hline 16 & Trauma - tibial nails & 3 & 6 & 1 & 6 & 1 & 17 & 13 \\
\hline 17 & Hand - tendon repair & 3 & 3 & 1 & 13 & 1 & 21 & 17 \\
\hline 18 & Trauma $-\mathrm{MUA}^{\dagger}+$ Kirschner wiring & 3 & 4 & 8 & 59 & 8 & 82 & 71 \\
\hline
\end{tabular}

* ORIF, open reduction and internal fixation

† MUA, manipulation under anaesthesia

A, assisted; STS, surgeon with trainer scrubbed; STU, surgeon with trainer present but unscrubbed; $\mathrm{P}$, surgeon with trainer available but not in the operating room; $\mathrm{T}$, teaching junior surgeon

often enough to allow reliable measurement. They allow data capture through observations of a series of similar events. This is akin to the mini clinical examination and history taking skills (CEX) and simple practical procedures such as establishing an intravenous line which are based on work by Norcini et al. ${ }^{3}$ They found that snapshots of clinical activity can be used reliably provided about 15 similar but unrelated events are assessed by properly trained observers. The Royal College of Physicians expects about 40 CEX's to be provided over the five years of Higher Medical Training (personal communication).

OCAP uses a Delphi method (consensus of an expert group) of validating performance-based assessment. We identified 18 activities which were felt by a nominated group of experts to be representative of trauma and orthopaedic surgery. These include work in the wards and clinics, and commonly performed operations (Table I). Each operation is split into domains, including consent, common to pre-operative planning, preparation and surgical technique. Each domain has further components, the majority being all the performance-based assessments and all can be related to the outcomes defined in 'Good Clinical Practice'. In each domain the trainee is required to demonstrate evidence of knowledge and skills (Table II).

In order to validate the performance-based assessment and its domains, meetings of trainers and trainees took place in two regions of the United Kingdom. These were followed up by postal questionnaires. The overwhelming response was that the instruments are relevant, easily usable and supported the impression of the Delphic groups, confirming that the identified performance-based assessments are realistic.

More recently we correlated the current performancebased assessment with the frequency of activity reported in the National Trauma and Orthopaedic Log Book..$^{5}$ Table III shows that in general the Delphi method of identifying commonly performed procedures is confirmed. However, there are problems ensuring that the procedures are performed often enough to permit reliable interpretation of data. For example, there was strong consensus that the application of an external fixator contains unique competencies. However, trainees seldom encounter this procedure outside a specialist attachment. As Sher et $\mathrm{al}^{6}$ point out, unless all training opportunities are used it would be difficult adequately to assess competence in many procedures.

The strengths of OCAP include a consolidation sheet which not only lists procedures but also maps the domains of competency (Fig. 5). This permits a training director to record experience of core procedures and identify progress in the domains. For example, a trainee may be performing well technically but be consistently identified as a poor communicator. Such observations, especially when made 


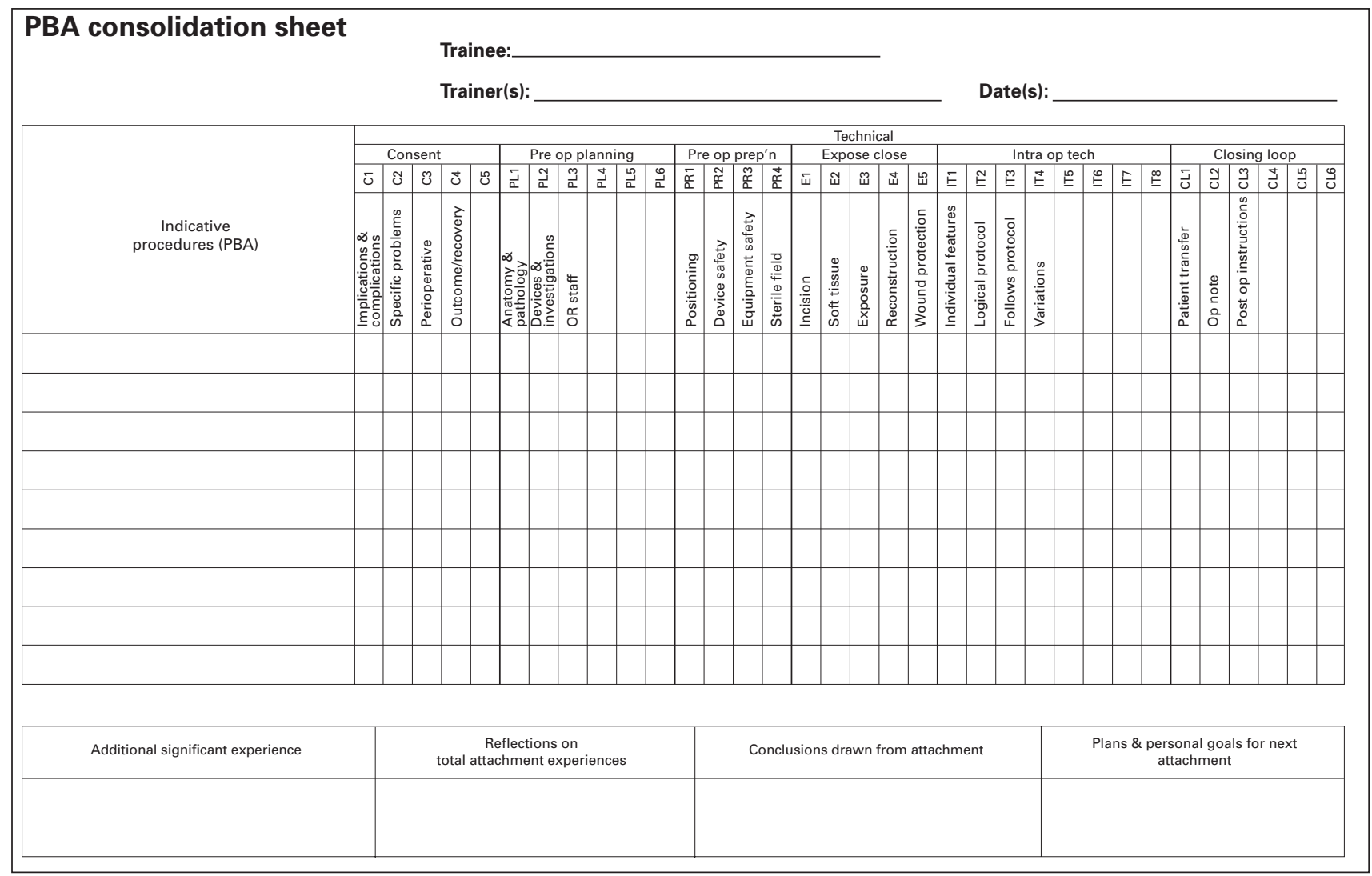

Fig. 5

An example of the performance-based assessment consolidation sheet

by different observers, provide powerful information for appraisal.

\section{The current status of OCAP}

OCAP instruments have been reviewed and triangulation studies indicate they are valid. Early work shows they are reliable and further inter-observer studies are under way. Trainers and trainees have been provided with a structure based on conventional educational instruments and given a means of mapping back to core competencies. The evolving synergy with the orthopaedic log book gives strong supporting evidence of training activity.

We now have a curriculum which meets the standards prescribed by national validating bodies and uses practicable language and taxonomy for trainers and trainees.
The authors acknowledge the contribution of the members of the OCAP steering group (Tony Banks, Peter Briggs, Nick Clarke, Chris Howell, John Edge, Alan Norrish, Phil Turner, Keith Willett) and numerous trainers and trainees who continue to make invaluable contributions to the project.

\section{References}

1. Miller GE. The assessment of clinical skills/competence/performance. Acad Med 1990;65(9 Suppl):63-7.

2. Norman G. Examining the examination: Canadian versus US certification exam. Can Assoc Radiol J 2000;51:208-9.

3. Norcini JJ, Blank LL, Duffy FD, Fortna Gregory S. The mini-CEX: a method for assessing clinical skills. Ann Intern Med 2003;138:476-81.

4. Good medical practice. Third ed, May 2001. http://www.gc-uk.org (accessed 16.6.05).

5. National Orthopaedic and Trauma Log Book. Faculty of Health Informatics, Royal College of Surgeons of Edinburgh.

6. Sher L, Reed M, Calvert P, Wallace A, Lamb A. Influencing the national training agent: the UK \& Ireland orthopaedic eLogbook. J Bone Joint Surg [Br] 2005:87-B: $1182-6$. 